\title{
Application of Situational Virtual Reality System to improve Learning Performance of Traditional Hair Cutting Skills
}

\author{
Huang-Chu Hsu \\ Department of Digital Media Design, \\ Asia University, Taichung, 413, Taiwan \\ Sheng-Min Hsien \\ Department of Visual Communication Design, \\ Asia University, Taichung, 413, Taiwan \\ Rong-Chi Chang \\ Department of Technology Crime Investigation, \\ Taiwan Police College, Taiwan
}

\begin{abstract}
The study mainly relates to design and develop a system of "Hair Cutting and Blowing skills training" to assist hairdressing skills learning by theming on two major items of "hair cutting and blowing" skills" in the "Women's Hairdressing Certification C" test. The study has set 40 students who major in Fashion Modeling Department in northern Taiwan as experimental samples, wherein 20 students of experimental group were trained in the virtual reality hairdressing and hygiene skills training system; and 20 students of the control group were trained in traditional teaching methods. The result of the study has found that the experimental group's learning performance in the comprehensive skills is better than the control group, and the growth rate also reached a significant level. Through the test of the technology acceptance model, this "Hair Cutting and Blowing skills training" system can assist in the learning of skills and enhance students' motivation in learning. From unfamiliar skill training to proficiency, through the repeated practice in the virtual reality simulation environment, it helps in increasing hand feeling and confidence which can also help to reduce the amount of exercise materials needed for hair and blowing skills training.
\end{abstract}

Keywords : Virtual Reality, Hair Cutting, Blowing skills, Motivation, Digital Technology,

\section{INTRODUCTION}

In recent years, Head-mounted Display (HMD) technology has been continuously improved. (Wang et al., 2016; Xu, Chen, Lin, \& Radwin, 2015) The related research of Virtual Reality (VR) has a critical breakthrough. Many immersion VR studies have begun to receive academic emphasis and application. (Kaufmann, Schmalstieg, \& Wagner, 2000; Merchant, Goetz, Cifuentes, Keeney Kennicutt, \& Davis, 2014). For instance, Grabowski and Jankowski (2015) carried on education the highly dangerous underground coal miners; Bertram, Moskaliuk, and Cress (2015) designed relevant courses for the policemen's duty missions. Some scholars have also applied a VR environment to construct an operating room scene (Palter, Palter, Sobko Koziupa, Gilhuly, \& Pyer, 2000; Sankaranarayanan et al., 2016) and simulate patient's physical condition and provide surgeons with HMD interface learning and pre-operation. Related surgical procedures. The scene constructed by VR technology provides a sense of realism that was previously unattainable in multimedia projection technology. It allows learners to practice in a safe environment in accordance with their own learning. In addition to enhancing learning 
motivation and strengthening the internalization of knowledge; more importantly, it can avoid harm to body safety or permanent damage to the environment due to improper operations.

The extent which learners are immersed in VR scenarios often affects their learning motivations and learning outcomes (Lackey, Salcedo, Szalma, \& Hancock, 2016). Therefore, in order to immerse learners in a virtual environment, we must first effectively simulate various conditions of the real world and avoid interfering from the real environment at the same time. When the user is provided with sufficient presence in the VR environment, learners can focus on the teaching activities and be further leaded to an emotional experience of people living in a real life (Parsons \& Rizzo, 2008). By setting HMD device as a learning environment for the VR user, it can provide more sense of presence than the situation simulated on the flat screen, which can lead to emotional experience in learning, and make learners more immersed in the learning process as well.

The study shall apply HMD as a user interface to construct a "Hair Cutting and Blowing Skills Training" system by using VR technology to provide a safe and realistic learning environment. This system has broken through the limitations of time, space and materials, and designed first-person hair cutting and blowing skills training in use. The study also analyzes the learning motivation and learning effectiveness in object to HMD human-machine interface users in a VR environment. It is expected that the study results can promote the training mode of traditional hair cutting skills as well as enhance the learners' learning effects in hair cutting and blowing.

\section{Virtual Reality}

\section{LITERATURE REVIEW}

The virtual reality has been developed for more than half a century (Heiling, 1962), which mainly applies various simulated media or media to stimulate human senses, so that people can be placed in the created virtual world but have a very similar feeling to the real world.

Since people are more dependent on vision than the stimulus provided by other senses, most of today's VR systems apply computer and multimedia technology as main media. VR emphasizes on creating realistic 3D visual effects and creating an environmental feeling that makes people unable to distinguish between true and false feeling (Bell, 1996). Recently, HMD displays have been used in conjunction with gyroscopes as motion detection sensors for neck movement. Due to the maturity of vision and displacement synchronization technology, it can not only eliminate the dizziness problems common in VR vision, but also break through the limitations that users can only passively observe in the VR environment and provide a more realistic interaction.

VR technology is integrated into various skills training, and there are many successful cases developed in its field. The study by Xiao, Wen, Hung-Lin, Albert, and Xiangyu (2018) found that through VR development technology, operators in the construction industry were taught to conduct experience training in the security field to visualize complex work scenarios, and to effectively establish security mechanisms and skills. The integration of high-risk machine operation with the VR environment can reduce the empirical difference between VR and actual operations. Therefore, the application of VR system can effectively promote the educational value in hazard identification, safety training education, and safety inspection. Virtual Reality can provide interactive learning between learners and textbooks and build an immersive learning environment that guides learners to actively participate in learning activities, and also provides opportunities for learners to practice repeatedly to improve learning efficiency (Neil Vaughan \& Bodgan Gabrys \& Venketesh N., 2016). 
Salehie (2009) found that in traditional learning, educational training requires a lot of human supervision to teach and require many expensive labor costs and learning consumables (Park \& Lee, 2003). Kardan \& Aziz (2015) VR technology will be shifted to more learner-centric approaches. The application of VR technology to be integrated with the skills training education and to customize the content of the textbooks to meet learners' needs, interests, goals and backgrounds, so that learners can timely adjust their learning progresses and learning ways.

\section{Situated Learning}

Situated Learning is often used in learning activities supported by science technology. Situated Learning allows learners to learn in the knowledge environment constructed by the learning topics and focus their learning activities on problem solving techniques. Situational learning relates to learning, experience learning, active learning, and learning at the learner center, etc. The concept of situational learning is to set learning in real or simulated situations. Through the interaction between learners and situations, students can apply the acquired knowledge more effectively in a real life. Therefore, situational learning is contextualized in the environment and requires direct interaction between students and real experiences.

People like Jonassen (1994) rethink the relationship among media, teaching methods, learners and learning situations and view learning from a systematic perspective and an overall angle, and take media as part of the learning process. Situational learning emphasizes learners' subjectivity in the learning process. Teachers should understand the interactions among media, teaching methods, learning situations and learners in order to find a combination that is conducive to learning and achieve the most effective interaction. Situational learning advocates that students construct knowledge in the process of interaction and apply knowledge to turn students from passive to active. Learning can happen only through actual situations.

The main feature of virtual reality is immersive reality. The study has adopted contextual learning to provide a near-realistic scenario of "Hair cutting and blowing skills training" by applying the virtual reality constructed by HMD. We design first-person learning content and simulate the characteristics and rules of hair cutting, blowing and health knowledge and skills training so that the learners can experience the real environment and learn related knowledge and skills in an interactive mode.

\section{System Development}

The study mainly relates to apply Unity 3D game engine as a development tool, and HMD as the operation interface to develop a "VR Hair Cutting and Blowing Skill Training" system. This system consists of two main concepts: teaching guidelines and interactive operations. The content contains knowledge and skills such as hair cutting, blowing, and hygiene concepts. Learners can enter the system through an account to learn according to the learning process. Each unit has course descriptions, example operations, problem feedback and assessments. Through the automatic recording and checking mechanism of the system, learners can obtain the system's score and view a personal self-operation process after completing the task. The related interface of the system is shown as Figure 1. 


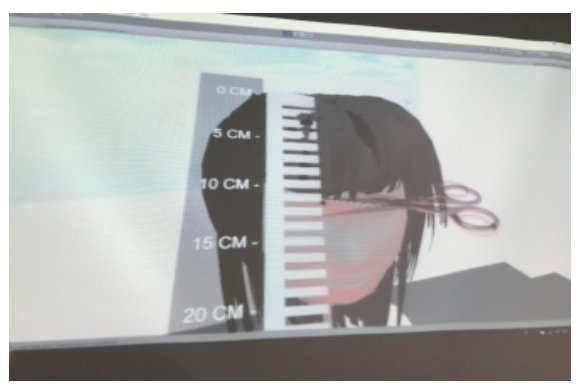

(a)

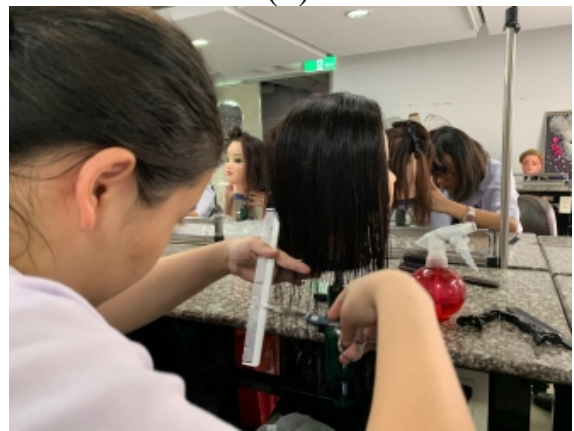

(c)

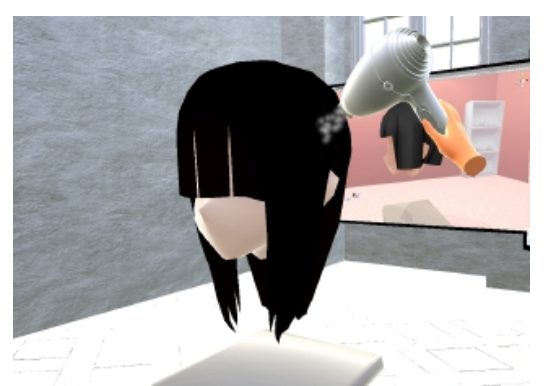

(b)

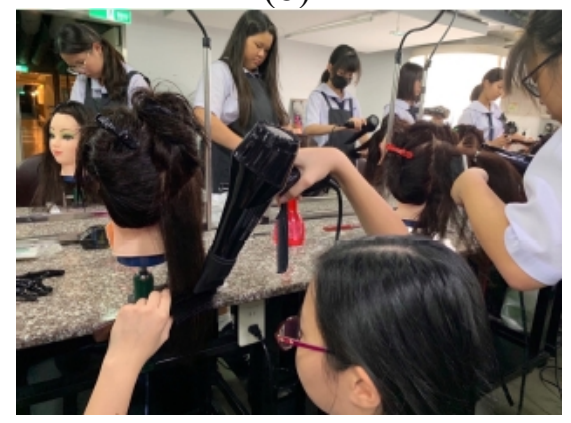

(d)

Figure 1: (a) VR hair cutting interaction operation (b) VR hair blowing interaction operation (c) traditional hair cutting skill training (d) traditional hair blowing skill training

\section{RESEARCH METHODS}

The purpose of the study is to investigate the impact of traditional learning and training processes on hair cutting and blowing skills in a VR learning environment. Through the context design, teaching guidelines, interactive feedback and assessment system, students can understand the motivation, effectiveness and acceptance of the system.

\section{Participants}

Participants in the study were 40 Northern Taiwanese fashion styling majors aged from 17 to 19. Among them, 20 students were Experimental Groups and 20 students were Control Groups. Both groups are taught and coached by the same teacher. Participants were students who wished to take Women's Hairdressing Class C Technical Test.

Two groups of students implemented the pre-test and pre-learning questionnaires before the start of the course to ensure that two groups of students had no significant differences in the prior knowledge of hair cutting, blowing and health knowledge. At the beginning of the experiment, Experimental Group had a description course of VR system operation and demonstration to ensure that students could understand how to operate the "VR hair cutting and blowing skill training" system. After that, two groups of students conducted different learning activities. Experimental Group used the "VR hair cutting and blowing skill training" system to learn; Control Group was supplemented by film learning in a traditional teaching mode. After the activity ended, two groups conducted post-test and post-learning questionnaires. The experimental flow is shown as Figure 2.

The questionnaire was measured before and after the experiment to understand whether the learner's motivation before and after the experiment was affected. In addition, after the study, through Technology Acceptance Questionnaire, students could understand the degree of acceptance of technology guided teaching. 


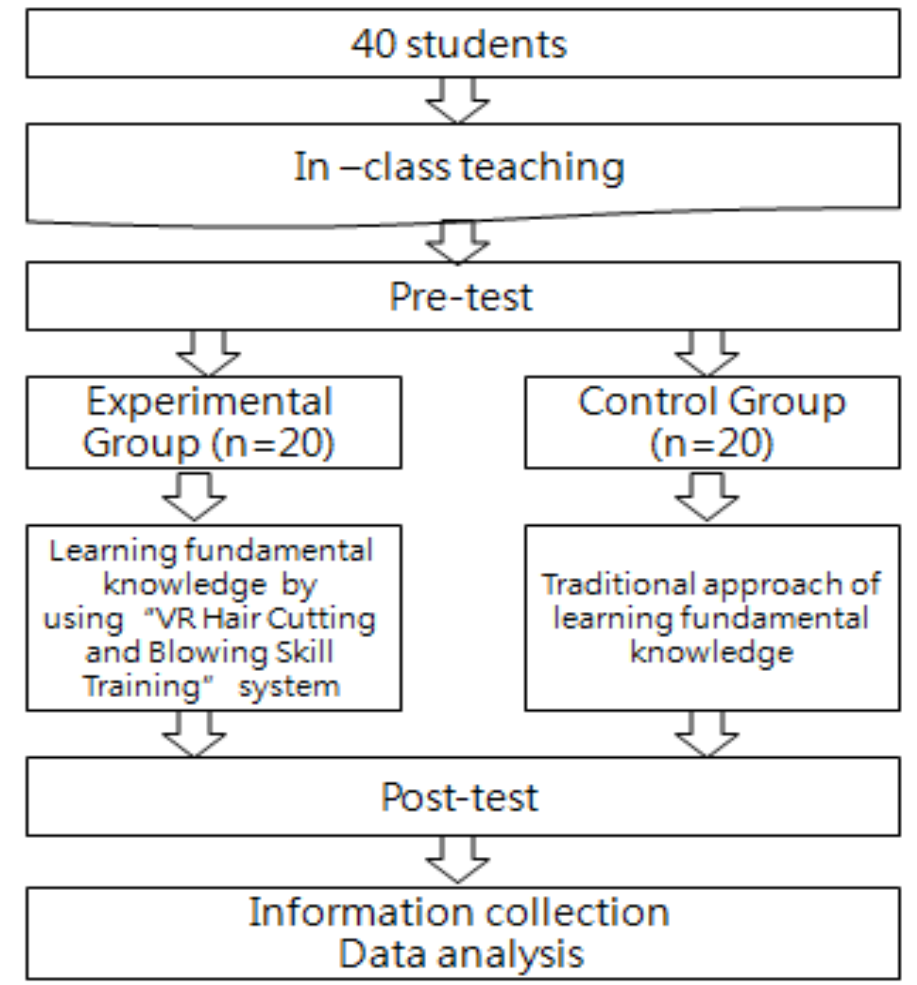

Figure 2. Experimental flow
4 weeks

30 mins

2 weeks

30 mins

\section{Research tools}

The research tools of this experiment include learning achievement tests and questionnaires. The questionnaires are used to test students' motivation and technology acceptance. The content of the achievement test is proposed by the instructors from "Woman's Hairdressing Class C Technical Test" question database. It includes 10 questions (40 points) of hair cutting and blowing, and 20 questions (100 points) of basic hygiene knowledge with a total point of 140 points. Pre-tests are provided to understand in advance students' knowledge of hair cutting, hair blowing and hygiene. The post-test topic plan is similar to the pre-test.

The Science and Technology Acceptance Measurement form shall be filled out after the experiment. The Science and Technology Acceptance Measurement form used in the study was reedited from Chu, Hwang, Tsai \& Tseng (2010). The questionnaire contains two aspects of "Perceived Usefulness" and "Perceived Easy Usefulness" with a total of 13 questions, which use Likert 5-point measurement. "Perceived Usefulness" mainly investigates whether users' perceptions of learning tools are helpful for learning. "Perceived Easy Usefulness" is used to explain whether it is easy for learners to use in learning tool operations.

\section{Learning achievement}

\section{FINDINGS \& DISCUSSION}

In order to understand whether two groups of students had same prior knowledge before the learning activities, the pre-test scores were independently tested and two groups were evaluated for their basic ability in hair cutting, blowing and hygiene knowledge before the experiment. The statistical results from the previous test showed that the average score of Experimental Group was 115.65 points, and the average score of Control Group was 116.45 points. There was no significant difference in the prior knowledge between Experimental Group and Control Group ( $t=2.381, p>0.1)$, which did not reach a statistical level. It showed the ability of both Experimental and Control Groups have the same knowledge of hair cutting, hair blowing and hygiene knowledge before the experiment. 
In order to compare whether the learning effect between Experimental Group and Control Group has reached a significant difference, a paired sample was tested for a pre-test result. The result of the experimental analysis (as shown in Table 1), post test score of Experimental Group was 125.95 points, post test score of Control Group was 122.85 points. After comparing the difference between two groups, Experimental Group was improved by 10.3 points compared with the pre-test, and Control Group was improved by 6.4 points. The scores of two groups were better than those of Control Group. In other words, learning through the "VR Hair Cutting and Blowing Skill Training" system had better learning effect than the traditional information integrated learning.

Table 1: Analysis of the scores between pre-test and post-test of hair cutting and blowing and hygiene knowledge

\begin{tabular}{|c|c|c|c|c|c|c|c|c|}
\hline & \multirow{2}{*}{$\mathrm{N}$} & \multicolumn{2}{|c|}{ Pre-test } & \multicolumn{2}{|c|}{ Post-test } & \multirow{2}{*}{$\begin{array}{l}\text { Posttest - } \\
\text { pretest }\end{array}$} & \multirow{2}{*}{$t$} & \multirow[b]{2}{*}{$p$} \\
\hline & & M & S.D. & M & S.D. & & & \\
\hline $\begin{array}{l}\text { Experimental } \\
\text { group }\end{array}$ & 20 & 115.65 & 6.706 & 125.95 & 8.211 & 10.3 & $4.533^{* *}$ & .000 \\
\hline Control group & 20 & 116.45 & 7.870 & 122.85 & 8.518 & 6.4 & $2.868^{*}$ & .010 \\
\hline
\end{tabular}

\section{Technology acceptance}

In order to understand the impact of Experimental Group on the guided course of the "Hair Cutting and Blowing Skills Training" system, Experimental Group implemented Science Acceptance Measurement after study. The test questions include "Cognitive usefulness" and "Cognitive Easy Usefulness," and are scored by using Likert 5-point measurement. As shown in Table 2, the technical acceptance of Experimental Group has a good score in "Perceived usefulness" and "Perceived ease of use" projects. The functions and interfaces of "Hair Cutting and Blowing Skills Training" system are well designed and learners have high acceptance.

Table 2: Analysis statistics for technology acceptance of experiment group

\begin{tabular}{ccc}
\hline \hline items & Mean & S. D. \\
\hline Perceived usefulness & 4.47 & .643 \\
\hline Perceived ease of use & 4.16 & .851 \\
\hline
\end{tabular}

\section{CONCLUSION}

Traditional hairdressing skills learning is mainly guided and trained by an apprenticeship system. Through the guidance and assistance of the instructors, learners can gain professional knowledge and professional skills as well as inherit the experience and skills. Hair cutting technology course emphasizes the importance of "Hands Operated", and repeated exercises will surely promote the professional ability of hair cutting skills. The establishment of a Virtual Reality environment of which the operation is similar to actual working environment shall be helpful in increasing the chances of skill operation. The purpose that the study develops "Hair Cutting and Blowing Skills Training" system is to create interactive operations and multiple experience opportunities in a Virtual Reality environment. The study found that "Hair Cutting and Blowing Skills Training" system guided the hairdressing skills teaching course to effectively promote learning effects. Learning through the "Hair Cutting and Blowing Skills Training" system also increases the proficiency and skill of professional skills. According to the 
learner's reaction, "Hair Cutting and Blowing Skills Training" system has a fine interface design and function, which is suitable to be used in supplementary teaching of skills training course.

\section{Reference}

Bertram, J., Moskaliuk, J., \& Cress, U. (2015). Virtual training: Making reality work? Computers in Human Behavior, $43,284-292$.

Chu, Hui-Chun \& Hwang, Gwo-Jen \& Tsai, Chin-Chung \& Tseng, Judy. (2010). A two-tier test approach to developing location-aware mobile learning system for natural science course. Computers \& Education. 55. 16181627.

Grabowski, A., \& Jankowski, J. (2015). Virtual Reality-based pilot training for underground coal miners. Safety Science, 72, 310-314.

Heiling, M. (1962). Sensorama simulator: US Patents: US3050870A

Jonassen, D. (1994). Learning with Media; Restructuring the Debate. Educational Technology, Research and Development, 42(2), 31-39.

Kardan, A. A., Aziz \& Shahpasand, M. (2015).Adaptive systems: A content analysis on technical side for e-learning environments. An International Science and Engineering Journal, 44(3), 365-391.

Kaufmann, H., Schmalstieg, D., \& Wagner, M. (2000). Construct3D: A Virtual Reality Application for Mathematics and Geometry Education. Education and Information Technologies, 5(4), 263-276.

Lackey, S. J., Salcedo, J. N., Szalma, J. L., \& Hancock, P. A. (2016). The stress and workload of virtual reality training: the effects of presence, immersion and flow. Ergonomics, 1-13.

Merchant, Z., Goetz, E., Cifuentes, L., Keeney Kennicutt, W., \& Davis, T. (2014). Effectiveness of virtual reality-based instruction on students' learning outcomes in K-12 and higher education: A meta-analysis. Computers \& Education, 70, 29-40.

Neil, Vaughan \& Bodgan, Gabrys \& Venketesh, N. Dubey (2016). An overview of self-adaptive technologies within virtual reality training. Computer Science Review, 22(1), 65-87.

Palter, S. F., Palter, S. F., Sobko Koziupa, O., Gilhuly, T., \& Pyer, C. (2000). Use of a Head Mounted Display (HMD)

Virtual Reality (VR) Headset as a Patient Distraction Device for Surgical Procedures Under Local

Anesthesia/Sedation. Fertility and sterility, 74(3), S203-S203.

Park, O.-C. \& Lee, J. (2003). Adaptive instructional systems. Educational Technology Research and Development, 25(1), 651-684.

Parsons, T. D., \& Rizzo, A. A. (2008). Affective outcomes of virtual reality exposure therapy for anxiety and specific phobias: A meta-analysis. Journal of behavior therapy and experimental psychiatry, 39(3), 250-261.

Salehie, M. \& Tahvildari, L. (2009).Self-Adaptive Software: Landscape and Research Challenges.ACM Transactions on Autonomous and Adaptive Systems (TAAS), 4(2), 1-42.

Ganesh Sankaranarayanan Baichun LiKelly Manser Stephanie B. Jones Daniel B. Jones Steven Schwaitzberg Caroline G. L. Cao Suvranu De (2016). Face and construct validation of a next generation virtual reality (Gen2-VR) surgical simulator, Surgical Endoscopy. 30(3), 979-985.

Wang, Yunqi \& Liu, Weiqi \& Meng, Xiangxiang \& Fu, Hanyi \& Zhang, Daliang \& Kang, Yusi \& Feng, Rui \& Wei, Zhonglun \& Zhu, Xiuqing \& Jiang, Guohua. (2016). Development of an immersive virtual reality head-mounted display with high performance. Applied optics. 55. 6969-6977.

Xiao, Li \& Wen, Yi, Hung, Lin. Chi, Xiangyu, Wang \& Albert, P.C. Chan(2018).A critical review of virtual and augmented reality (VR/AR) applications in construction safety. Automation in Construction, 86(2), 150-162.

Xu, X., Chen, K. B., Lin, J.-H., \& Radwin, R. G. (2015). The accuracy of the Oculus Rift virtual reality head-mounted display during cervical spine mobility measurement. Journal of Biomechanics, 48(4), 721-724. 